\title{
Peertechz
}

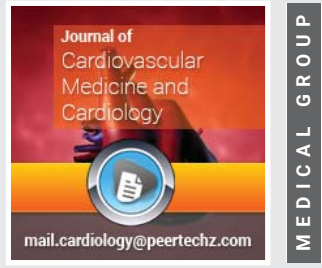

\section{Pregabalin overdose causing sinus bradycardia - A rare complication}

\author{
Rajesh Kumar*, Jathinder Kumar, Ihtisham Malik and \\ Gordon Pate
}

Department of Cardiology, University Hospital Limerick, Ireland

Received: 25 January, 2021
Accepted: 13 February, 2021
Published: 15 February, 2021

*Corresponding author: Dr. Rajesh Kumar, Department of Cardiology, University Hospital Limerick, Ireland, Tel: +353834433619; E-mail: rajesh2k7@yahoo.com

Keywords: Bradycardia; Overdose; Pregabalin

https://www.peertechz.com

Check for updates

\section{Abstract}

We present the unique case of severe, symptomatic bradycardia associated with pregabalin overdose. Pregabalin is a widely prescribed drug not routinely associated with sinus bradycardia. A 39 year old male, presented having taken about $4 \mathrm{~g}$ of pregablin with intention to self-harm. Following admission, he subsequently developed bradycardia on telemetry. Other possible causes were excluded with serial investigations. The bradycardia resolved by 96 hours without the need for temporary pacing. Patients presenting with pregabalin overdose should be monitored for bradycardia.

\section{Abbreviations}

MRI: Magnetic Resonance Imaging; CXR: Chest X-Ray; CT: Computerized Tomography; ECG: Electrocardiogram; GCS: Glasgow Coma Scale

\section{Introduction}

Pregabalin is a synthetic derivative of the inhibitory neurotransmitter gamma-amino butyric acid. It has anticonvulsant, analgesic, anxiolytic and sleep-modulating properties and is widely used in clinical practice [1]. Advantages of pregabalin include its relative reliability, ease of use, high tolerance and relatively low interaction with other drugs. Pregabalin binds to $\alpha 2 \delta 1$ subunit of Voltage-Gated Calcium Channels (VGCC) in the Central Nervous System (CNS) to decrease the release of several neurotransmitters which are responsible for mediating its anti-nociceptive and anti-seizure effects [1]. Pregabalin has oral bioavailability of $\geq 90 \%$, with maximal plasma concentration in approximately 1 hour, with a mean elimination $t_{1 / 2}$ of 6.3 hours, independent of dose [1]. Over-dosage has been described [2,3]; side effects though are mainly limited to central nervous system, but there are few published data regarding negative cardiac effects [4-7]. We report a unique case of management of severe symptomatic bradycardia secondary to pregabalin overdose, to make clinicians aware of this possibility.

\section{Case presentation}

A 39 year old man was brought to the hospital emergency department by ambulance after his father found him unconscious at home with an empty bottle of pregabalin tablets by his bedside. He had a history of depression, intravenous drug abuse and was an active cigarette smoker. His regular medications for the previous two years included duloxetine 120mg for depression, pregabalin $75 \mathrm{mg}$ twice daily for anxiety and zopiclone $7.5 \mathrm{mg}$ for sleep disturbance, the prescription for all of which he had renewed the day before. Fifty-four tablets were missing from the pregabalin bottle $(4 \mathrm{~g})$ and it appeared these tablets were taken with intention to self-harm.

On initial examination in the emergency department, he was found to have multiple marks of deliberate self-harm. His GCS on presentation was $13(\mathrm{E}=4, \mathrm{M}=6, \mathrm{~V}=3)$. On examination his temperature was $36.9^{\circ} \mathrm{C}$, blood pressure $134 / 83 \mathrm{mmHg}$, heart rate $64 / \mathrm{min}$, respiratory rate of $16 / \mathrm{min}$, and $\mathrm{O}_{2}$ saturation $99 \%$ on ambient air, and the rest of his clinical examination was unremarkable. Routine laboratory analysis including full blood count, blood glucose, thyroid function test, liver, renal and coagulation profile were normal. His electrolytes were also normal, including calcium $2.26 \mathrm{mmol} / \mathrm{L}$ (normal, 2.10-2.6), magnesium 0.88 (normal, 0.66-0.97), potassium $3.7 \mathrm{mmol} / \mathrm{L}$ (normal, 3.0-4.9), sodium $145 \mathrm{mmol} / \mathrm{L}$ (normal, 135-147) and 
chloride $111 \mathrm{mmol} / \mathrm{L}$ (normal, 97-119). High sensitivity cardiac Troponin $\mathrm{T}$ was borderline elevated at $34 \mathrm{ng} / \mathrm{L}(<14)$, and repeat levels at 6 and 12 hours were 36 and 26 respectively.

Arterial blood gas was normal, with normal pH. His initial ECG (Figure 1A) showed normal sinus rhythm, rate 61 beats/ min. CT brain did not show any acute pathology. His urine toxicology was positive for opiates and benzodiazepines. Serum alcohol and aspirin levels were negative. His GCS improved to 15 over the period of next few hours. He was admitted on telemetry for observation with pregabalin overdose, on top of opiate and benzodiazepine use.

Several hours later he started complaining of numbness and weakness of his left arm, with power of $1 / 6$. He was reviewed by a neurologist and urgent MRI brain, MRI Cervical and Thoracic spine which did not find any other pathology to explain his symptoms of weakness and numbness. He also became bradycardic with heart rate of $42 / \mathrm{min}$ (Figure $1 \mathrm{~B}$ ). His transthoracic echocardiogram confirmed normal structure and function of his heart with ejection fraction $>55 \%$. He was continuously monitored and on Day 2, his heart rate dropped as low as 29 beats per minute. Despite the bradycardia, his blood pressure remained stable and he was alert and oriented, therefore the decision was made to continue observation rather than insert a temporary pacing wire. Given the half-life of pregabalin, 6 hours, [1], he was monitored for an extended period of time and by day 4 of his admission his bradycardia resolved (Figure 1C) and he also had complete resolution of his neurological symptoms. His repeat bloods including electrolytes remained normal repeatedly during his admission.

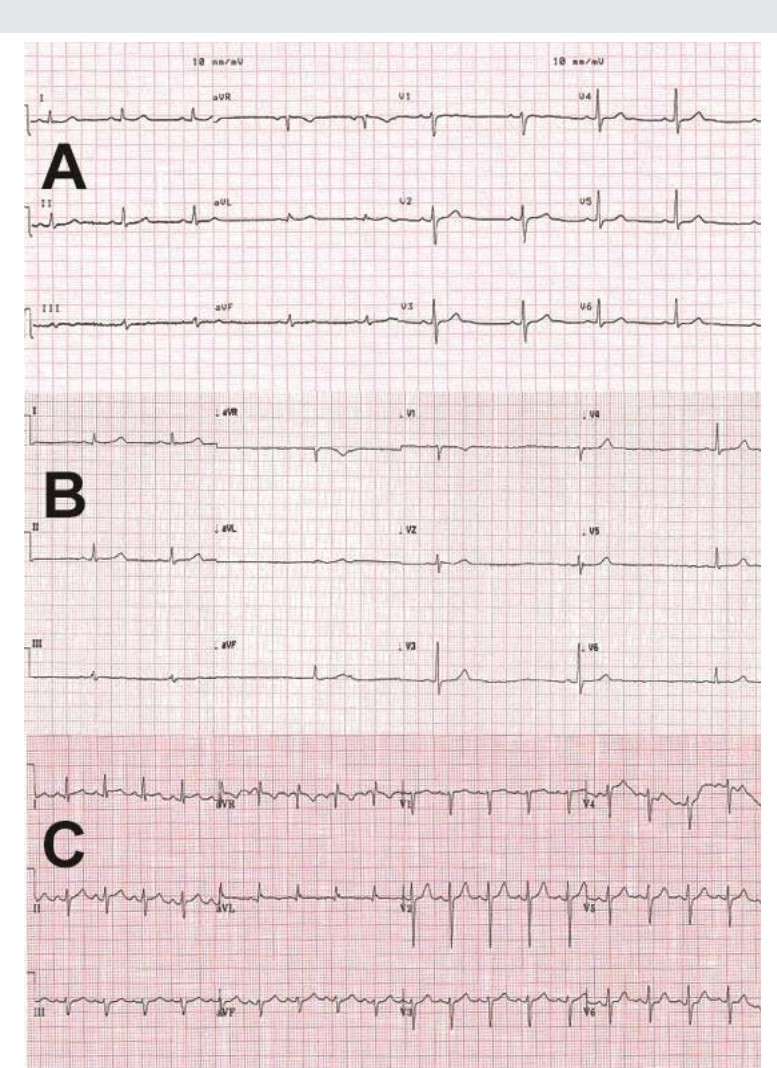

\section{Discussion}

We report here the first case of symptomatic prolonged sinus bradycardia with pregabalin overdose. Though pregabalin has been available for many years, there are no previous literature reports of overdose causing prolong, severe (rate less than 30 beats/min) symptomatic sinus bradycardia, though there is one report of complete heart block with pregabalin [6] and another of first degree heart block [7]. Summary of the product literature does suggest sinus bradycardia as a potential rare side effect [8] but limited literature to date exists to suggest how symptomatic, prolonged or severe the bradycardic effect can be. There is no literature to date to suggest the best treatment strategy or specific antidote in these rare cases.

This patient had also taken opiates and benzodiazepines; though these are not known to cause bradycardia, it is possible that the combination may have contributed to the development of sinus bradycardia. Other potential differentials like transient ischemic attack, hypoglycemia, stroke, psychiatric conditions, inflammation and infection of CNS, acute coronary syndromes needs to be ruled out in these patients with appropriate investigations.

The mechanism for sinus bradycardia with pregabalin is unknown. Cardiac myocytes possess 2 types of calcium channels; the L-type mainly in ventricles and T- type mainly in conduction tissue. Pregabalin is known to block calcium channels $[5,6,9]$. Therefore, as well as affecting the L-type calcium channels in the myocardium, pregabalin could potentially affect the $\mathrm{T}$-type calcium channels in myocardial conduction tissue, including the sinus and atrioventricular nodes $[9,10]$. One of the proposed mechanisms for prolonged bradycardia is that an excessive dosage/overdose of pregabalin could have led to potent reversible blockage of T-type VGCC causing prolonged sinus bradycardia, as seen in our patient. Severe symptomatic bradycardia as in our case, could have potentially led to a pacemaker insertion, which we avoided by a period of observation.

Evidence suggests that the potential of gabapentinoid abuse has increased in last few years in the intentional abuser group $[2,3]$, hence we highlight this rare possibility in pregabalin overdose to cardiologists, physicians and emergency clinicians. This case report suggests that pregabalin overdose can result in prolonged symptomatic bradycardia that can persist for upto 96 hours and prolonged cardiac monitoring should be performed in suspected cases.

\section{Consent}

The authors confirm that written consent for submission and publication of this case report including images and associated text has been obtained from the patient in line with COPE guidance.

\section{References}

1. Ben-Menachem E (2004) Pregabalin pharmacology and its relevance to clinical practice. Epilepsia 45: 13-18. Link: htps://bit.ly/3tWUIbA 
2. Evoy KE, Morrison MD, Saklad SR (2017) Abuse and Misuse of Pregabalin and Gabapentin. Drugs 77: 403-426. Link: https://bit.ly/2Z9SXdc

3. Daly C, Griffin E, Ashcroft DM, Webb RT, Perry IJ, et al. (2018) Intentional Drug Overdose Involving Pregabalin and Gabapentin: Findings from the National Self-Harm Registry Ireland, 2007-2015. Clin Drug Investig 38: 373-380. Link: https://bit.ly/3qurleZ

4. Page RL, Cantu M, Lindenfeld J, Hergott LJ, Lowes BD (2008) Possible heart failure exacerbation associated with pregabalin: case discussion and literature review. J Cardiovasc Med (Hagerstown) 9: 922-925. Link: https://bit.ly/3pg4m5P

5. Pregabalin: cardiac adverse effects (2014) Prescrire Int 23: 45.Link: https://bit.ly/3jIGV3Z

6. Aksakal E, Bakirci EM, Emet M, Uzkeser M (2012) Complete atrioventricular block due to overdose of pregabalin. Am J Emerg Med 30: 2101.e1-2101. e21014. Link: https://bit.ly/3tXwhLw
7. Schiavo A, Stagnaro FM, Salzano A, Marra AM, Bobbio E, et al. (2017) Pregabalin-induced first degree atrioventricular block in a young patient treated for pain from extrapulmonary tuberculosis. Monaldi Arch Chest Dis 87: 838. https://bit.ly/3aVUOru

8. Pfizer Australia Pty Ltd (2005) lyrica( pregabalin), ABN 5000842234838 - 42 edn., Wharf Road West Ryde NSW 2114:pfizer.

9. Pexton T, Moeller-Bertram T, Schilling JM, Wallace MS (2011) Targeting voltage-gated calcium channels for the treatment of neuropathic pain: a review of drug development. Expert Opin Investig Drugs 20: 1277-1284. Link: https://bit.ly/379Xdha

10. Ono K, lijima T (2010) Cardiac T-type $\mathrm{Ca}(2+)$ channels in the heart. J Mol Cell Cardiol 48: 65-70. Link: https://bit.ly/2LKOv1i

\section{Discover a bigger Impact and Visibility of your article publication with} Peertechz Publications

\section{Highlights}

* Signatory publisher of ORCID

* Signatory Publisher of DORA (San Francisco Declaration on Research Assessment)

* Articles archived in worlds' renowned service providers such as Portico, CNKI, AGRIS, TDNet, Base (Bielefeld University Library), CrossRef, Scilit, J-Gate etc.

* Journals indexed in ICMJE, SHERPA/ROMEO, Google Scholar etc.

- OAI-PMH (Open Archives Initiative Protocol for Metadata Harvesting)

* Dedicated Editorial Board for every journa

* Accurate and rapid peer-review process

* Increased citations of published articles through promotions

* Reduced timeline for article publication

Submit your articles and experience a new surge in publication services (https://www.peertechz.com/submission).

Peertechz journals wishes everlasting success in your every endeavours.

Copyright: ( 2021 Kumar R, et al. This is an open-access article distributed under the terms of the Creative Commons Attribution License, which permits unrestricted use distribution, and reproduction in any medium, provided the original author and source are credited.

Citation: Kumar R, Kumar J, Malik I, Pate G (2021) Pregabalin overdose causing sinus bradycardia - A rare complication. J Cardiovasc Med Cardiol 8(1): 007-009. DOI: https://dx.doi.org/10.17352/2455-2976.000160 